\title{
Training in using maple and geogebra software for mathematics teachers in the environment SMA Negeri 15 Medan
}

\author{
Aghni Syahmarani ${ }^{* 1}$, Putri Khairiah Nasution ${ }^{1}$ \\ ${ }^{1}$ Departement of Mathematics, Universitas Sumatera Utara, Medan, Indonesia \\ *Email: syahmarani.aghni@gmail.com
}

\begin{abstract}
Currently there are lots of softwares to solve problems including math problems. Mathematics teachers are now starting to be demanded to be able to operate some mathematical software to be considered capable of adapting to scientific developments, especially information technology at this time. For this reason training is needed for mathematics teachers so that they can master some mathematical software so that they become professional and more competent teachers. Dedication to this community will provide training to mathematics teachers, especially mathematics teachers in SMA Negeri 15 Medan to be able to use two pieces of mathematical software namely MAPLE and GEOGEBRA so that the competencies of these mathematics teachers increase and be more updated with technology.
\end{abstract}

Keyword: Maple, geogebra

\begin{abstract}
Abstrak
Saat ini terdapat banyak sekali software-software untuk menyelesaikan persoalan termasuk persoalan matematika. Guru matematika saat ini mulai dituntut untuk bisa mengoperasikan beberapa software matematika agar dianggap mampu beradaptasi dengan perkembangan keilmuan khususnya teknologi informasi saat ini. Untuk itulah dibutuhkan suatu pelatihan untuk guru matematika agar mereka dapat menguasai beberapa software matematika supaya mereka menjadi guru-guru yang profesional dan lebih berkompeten. Pengabdian kepada masyarakat ini akan memberikan pelatihan kepada guru-guru matematika khususnya guru-guru matematika di SMA Negeri 15 Medan untuk dapat menggunakan dua buah software matematika yaitu MAPLE dan GEOGEBRA agar kompetensi guru-guru matematika tersebut meningkat dan lebih update terhadap teknologi.
\end{abstract}

Kata Kunci : Maple, geogebra

\section{PENDAHULUAN}

Pendidikan merupakan salah satu upaya untuk membangun dan meningkatkan mutu Sumber Daya Manusia (SDM) menuju era globalisasi yang penuh dengan tantangan, sehingga disadari bahwa pendidikan adalah sesuatu yang fundamental bagi setiap individu, oleh karena itu kegiatan pendidikan tidak dapat diabaikan begitu saja terutama dalam memasuki era persaingan yang ketat, tajam, dan berat pada abad 90 Dasriah M. Yahya, Tata Kelola Pembelajaran Berbasis ICT millenium ini (Rivai, 2010).

Dunia pendidikan saat ini dituntut untuk dikembangkanya pendekatan pembelajaran sesuai dengan dinamika pendidikan Negara kita, yang berakar pada UUD 45 dan UU no. 20 Tahun 2003 yang berakar pada nilai-nilai agama, kebudayaan nasional Indonesia dan tanggap terhadap tuntutan zaman dan sesuai dengan perkembangan IPTEK (Muhammad, 2015).

Keberadaan guru yang kompeten dan profesional merupakan salah satu persyaratan yang wajib dipenuhi guna meningkatkan kualitas pendidikan di Indonesia agar dapat bersaing dengan negara-negara maju lainnya. Salah satu indikator guru profesional dan kompeten adalah guru yang mampu beradaptasi dengan perkembangan keilmuan yang hari demi hari semakin canggih. Selain itu, guru yang profesional dan kompeten juga harus mampu menerapkan model dan metode pembelajaran berdasarkan tuntutan waktu dan kebutuhan peserta didik. 
Beberapa negara dibelahan dunia telah menerapkan konsep tersebut sejak lama. Alhasil, kualitas pendidikan mereka jauh lebih baik dan berkembang dengan cepat. Tak terbantahkan lagi dalam sejarah bagaimana Jepang dihancurleburkan dengan jatuhnya bom atom di Hiroshima dan Nagasaki. Tapi dengan modal pendidikan yang menjadi prioritas utama, Jepang bangkit bak meteor sehingga menjadi negara yang super maju baik dalam IPTEK maupun peradaban. Berbeda dengan Jepang, Malaysia yang pada tahun 1980an banyak mengimpor guru dan belajar dari Indonesia, dalam waktu relatif singkat mampu mensejajarkan dirinya dengan negara-negara maju lainnya di dunia. Hal tersebut dapat terjadi karena perhatian pemerintah yang sangat besar terhadap dunia pendidikan termasuk kualitas dan kesejahteraan guru (Nurdyansyah,2016).

Keberadaan guru yang kompeten dan profesional merupakan salah satu persyaratan yang wajib dipenuhi guna meningkatkan kualitas pendidikan di Indonesia agar dapat bersaing dengan negara-negara maju lainnya. Hampir semua bangsa di dunia ini selalu mengembangkan kebijakan yang mendorong terciptanya guru yang kompeten dan berkualitas. Salah satu indikator guru profesional dan kompeten adalah guru yang mampu beradaptasi dengan perkembangan keilmuan yang hari demi hari semakin canggih. Selain itu, guru yang profesional dan kompeten juga harus mampu menerapkan model dan metode pembelajaran berdasarkan tuntutan waktu dan kebutuhan peserta didik. Penerapan pola ini akan menciptakan suasana menyenangkan dalam belajar, enjoy dalam mengajar, yang pada akhirnya akan menghasilkan proses KBM yang berkualitas termasuk peserta didik yang berprestasi.

Di bidang matematika, sekarang ini banyak sekali terdapat software-software untuk menyelesaikan persoalan matematika. Guru matematika yang berkompetensi dengan teknologi informasi saat ini dituntut untuk bisa mengoperasikan beberapa software matematika tersebut agar guru tersebut dianggap mampu beradaptasi dengan perkembangan keilmuan khususnya teknologi informasi saat ini. Untuk itulah dibutuhkan suatu pelatihan khususnya untuk guru matematika agar mereka dapat menguasai beberapa software matematika supaya mereka menjadi guru-guru yang profesional dan lebih berkompeten serta menguasai teknologi.

SMA Negeri 15 Medan yang berlokasi di Jl Sekolah Pembangunan, Medan Sunggal merupakan salah satu Sekolah Menengah Atas Negeri di provinsi Sumatera Utara yang memiliki visi sekolah "BERPRESTASI, DISIPLIN, KOMPETITIF YANG DILANDASI IMAN, TAQWA DAN BERWAWASAN LINGKUNGAN". Pengabdian kepada masyarakat ini dilakukan di SMA N 15 Medan dengan mengadakan pelatihan penggunaan software matematika MAPLE dan GEOGEBRA kepada guru-guru matematika di SMA N 15 Medan sehingga guru-guru matematika di SMA N 15 Medan menjadi guru-guru yang profesional dan lebih berkompeten serta menguasai teknologi.

SMA Negeri 15 Medan memiliki 7 orang guru matematika. Secara akademik, guru matematika di SMA Negeri 15 tersebut sudah sangat kompeten, 3 orang guru sudah mendapat gelar Strata-2 dan 4 orang lagi Sarjana Pendidikan Matematika. Namun, mereka belum terlalu menguasai teknologi informasi terutama software matematika.

\section{METODE PELAKSANAAN}

Kegiatan pengabdian masyarakat dibagi kepada beberapa tahapan yaitu pelaksanaan secara rinci, yaitu:

a. Survey awal, yaitu peninjauan lokasi mitra dengan menggali informasi tentang fasilitas apa saja yang sudah dimiliki sekolah serta apa saja yang belum dan sangat dibutuhkan sekolah untuk mendukung proses belajar mengajar. Sehingga tujuan pendidikan nasional berupa pencapaian kompetensi siswa dapat terwujud. 
b. Pembuatan buku panduan atau modul pelatihan. Dalam tahap ini tim pelaksana menyusun dan merancang buku panduan pelatihan softare MAPLE dan GEOGEBRA.

c. Pelatihan Guru. Pada tahap ini guru matematika SMA Negeri 15 tersebut akan diberikan pelatihan penggunaan software MAPLE dan GEOGEBRA selama 2 hari pelatihan

d. Evaluasi dan monitoring. Pada tahap ini, tim pelaksana akan mengevaluasi bagaimana proses belajar mengajar khususnya kegiatan praktikum di laboratorium dengan meggunakan peralatan yang sudah disediakan sebelumnya. Dalam tahap ini juga dilakukan umpan balik untuk mengumpulkan masukan terhadap kegiatan pengabdian kepada masyarakat yang telah dilakukan di tempat mitra tersebut.

SMA Negeri 15 sebagai mitra pelaksanaan kegiatan Pengabdian Kepada Masyarakat berperan sangat kooperatif dalam mendukung pelaksanaan kegiatan ini. Kepala sekolah sangat menyambut baik kegiatan ini demi mendukung peningkatan mutu guru khusunya guru matematika. Pihak sekolah memfasilitasi pelaksanaan pelatihan penggunaan software MAPLE dan GEOGEBRA dengan mengizinkan penggunaan laboratorium komputer SMA Negeri 15 Medan sebagai lokasi dilaksanakannya kegiatan pelatihan tersebut

\section{HASIL DAN PEMBAHASAN}

SMA Negeri 15 merupakan SMA negeri di kota medan yang memiliki fasilitas pendudukung prosens belajar mengajar yang sudah cukup memadai. Mereka memiliki laboratorium komputer yang bagus dan fasilitas infokus yang lengkap di setiap kelas. Namun, peningkatan SDM khususnya peningkatan kualitas guru apalagi dengan kemajuan teknologi saat ini masih sangat dibutuhkan. Untuk itulah dilakukan pengabdian kepada masyarakat di sekolah ini guna meningkatkan pengetahuan guru khususnya guru matematika dalam penggunaan teknologi komputasi berupa software matematika, yaitu MAPLE dan GEOGEBRA.

Hal yang dilakukan tim pelaksana kegiatan Pengabdian Kepada Masyarakat ini dimulai dari peninjauan lokasi tujuan untuk pengumpulan data berupa jumlah guru matematika di sekolah tersebut. Proses selanjutnya persiapan pelatihan yaitu membuat modul pelatihhan MAPLE dan GEOGEBRA dilanjutkan dengan instalasi software tersebut di komputer laboratorium komputer sekolah. Selanjutnya dilakukan kegiatan pelatihan penggunaan software matematika MAPLE dan GEOGEBRA serta proses monitoring dan evaluasi.

Dalam persiapan pelatihan, tim pelaksana telah menyediakan buku panduan yang akan digunakan pada pelatihan softare MAPLE dan GEOGEBRA. Masing-masing guru matematika di SMA Negeri 15 diberikan sebuah buku panduan penggunaan software MAPLE dan sabuah buku panduan penggunaan software GEOGEBRA. 


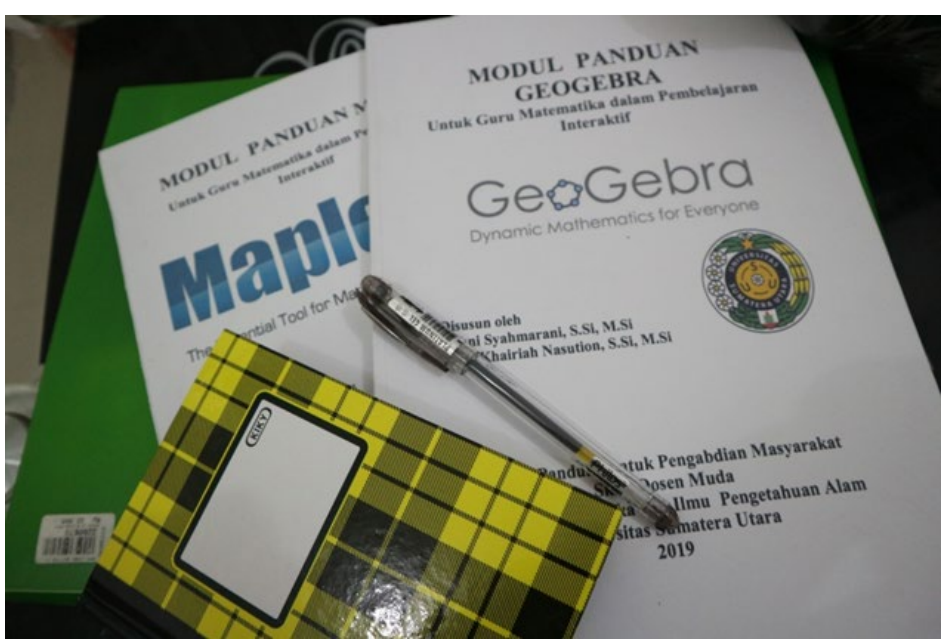

Gambar 3.1. Modul Pelatihan

Pelatihan MAPLE dan GEOGEBRA dilaksanakan di laboratorium komputer SMA Negeri 15 Medan dan dilakukan selama dua hari, hari pertama untuk pelatihan MAPLE sedangkan hari kedua untuk pelatihan GEOGEBRA. Peserta terdiri dari 7 orang guru matematika SMA Negeri 15 Medan. Kesulitan yang dihadapi dalam pelatihan hari pertama tersebut adalah karena ada 2 dari 7 orang guru matematika tersebut yang memang sudah berumur dan tidak begitu mahir mengoperasikan komputer sehingga proses pelatihan agak berlangsung lambat, karenanya pelatihan maple tersebut tidak tuntas dihari pertama dan dilanjutkan pada hari kedua selama 1 - 2 jam pertama. Kesulitan yang dihadapi selama pelatihan geogebra di hari kedua masih sama dengan hari pertama, namun karena keterbatasan waktu, pelatihan tersebut hanya difokuskan ke bagian yang dipilih oleh guru-guru tersebut, yaitu pengenalan geogebra dan pembuktian luas bangun datar.

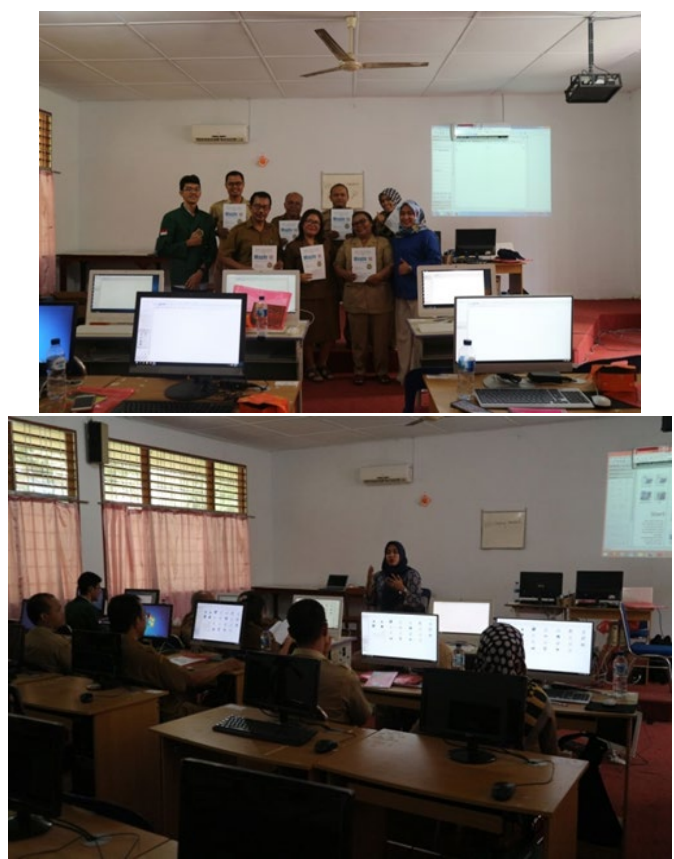

Gambar 3.2. Pelatihan

Monitoring, evaluasi dan diskusi feedback dilaksanakan 1 hari yaitu pada tanggal 15 November 2019. Kegiatan dimulai dengan monitoring dan evaluasi yaitu dengan menggunakan 
software MAPLE atau GEOGEBRA dikelas oleh guru dengan memperlihatkan kepada siswa bahwa ada teknologi untuk penyelesaian persoalan-persoalan matematika. Setelah itu, dilakukan diskusi dan evaluasi tentang penggunaan software MAPLE dan GEOGEBRA tersebut dengan membahas kesulitan-kesulitan yang dihadapi dalam menggunakan software tersebut dan kemudian didiskusikan solusi untuk kesulitan-kesulitan tersebut. Dari diskusi tersebut, diketahui beberapa kesulitan yang dihadapi para guru matematika antara lain:

1. Sebagian guru matematika di SMA Negeri 15 sudah berumur sehingga suit untuk memahami penggunaan teknologi khusunya teknolgi berbasis komputer seperti software. Sehingga tidak begitu mampu untuk menerapkan penggunaan software tersebut dalam pengajaran di kelas sehari-hari.

2. Karena keterbatasan waktu pelatihan, beberapa fungsi pada software tersebut belum bisa diterapkan. Tetapi sebagian besar sudah bisa diterapkan.

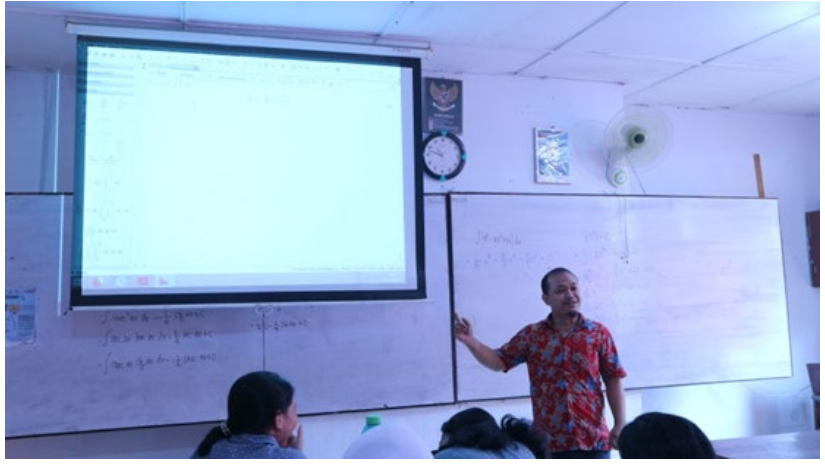

Gambar.3.3. Penggunaan software oleh guru dalam pengajaran

Jenis luaran yang dihasilkan dari kegiatan pengabdian masyarakat ini adalah :

1. Jasa berupa pelatihan penggunaan software MAPLE dan GEOGEBRA kepada guru-guru matematika di SMA Negeri 15 Medan

2. Buku panduan atau modul penggunaan software MAPLE dan GEOGEBRA untuk menjadi pegangan guru-guru matematika di SMA Negeri 15 Medan

3. Draft Artikel Ilmiah

4. Video Kegiatan yang akan di apload di YOUTUBE

\section{KESIMPULAN}

Adapun kesimpulan yang diperoleh dari kegiatan pengabdian masyarakat di SMA Negeri 15 Medan yaitu:

1. Kegiatan pengabdian masyarakat yang telah dilakukan mendapatkan respon yang luar biasa guru matematika dan kepala sekolah di SMA Negeri 15 karena memberika manfaat tambahan ilmu guna peningkatan kualitas guru matematika di lingkungan SMA Negeri 15 Medan

2. Terjadi peningkatan kemampuan guru khususnya kemampuan akan penggunaan software matematika sebagai objek dari pengabdian masyarakat ini.

3. Guru memiliki kemampuan menggunakan software matematika yang dapat digunakan dalam pengajaran.

\section{UCAPAN TERIMAKASIH}

Artikel ini merupakan salah satu hasil dari Program Pengabdian kepada Masyarakat yang Dibiayai oleh dana NON PNBP Universitas Sumatera Utara Sesuai dengan Surat Perjanjian Penugasan 
Pelaksanaan Pengabdian kepada Masyarakat Program Mono Tahun Dosen Muda Tahun Anggaran 2019. Oleh karena itu, diucapkan terima kasih kepada Rektor Universitas Sumatera Utara atas dukungan dana dan fasilitas yang diberikan. Terima kasih juga kepada Mitra pada kegiatan pengabdian ini.

\section{DAFTAR PUSTAKA}

Rivai. 2010. Education Management. Edisi kedua, Penerbit: Raja Garfinfo: Persada Jakarta

Muhammad, M., \& Nurdyansyah, N. (2015). Pendekatan Pembelajaran Saintifik. Sidoarjo:

Nizamia learning center., 41

Nurdyansyah, N. (2016). Developing ICT-Based Learning Model to Improve Learning Outcomes

IPA of SD Fish Market in Sidoarjo. Jurnal EKPEN, 1(2). Terbitan 2, 929-930. 